\title{
A New Record of Nyctalus furvus (Chiroptera: Vespertilionidae) from Korea, and the Description of Tadarida teniotis (Chiroptera: Molossidae), a Rarely Collected Bat in Korea
}

\author{
Myung Hee Yoon* \\ Department of Biology, Kyungsung University, Busan 608-736, Korea
}

\begin{abstract}
Taxonomic studies on two bat species, Nyctalus furvus Imaizumi and Yoshiyuki 1968 belonging to the Vespertilionidae, and Tadarida teniotis (Rafinesque) 1814 belonging to the Molossidae collected at Busan, Korea were carried out. The former, which has been known as an endemic species in Japan, is newly recorded in the Korean fauna and the latter is a very rare species which has not been collected since 1928 (Ognev, 1928) until two females were collected at Busan in this study, although Kishida and Mori (1931) reported the occurrence of the latter with no collecting record. Due to the addition of the former to the South Korean bat fauna, the bat fauna is composed of a total of twenty one species and one subspecies belonging to three families.
\end{abstract}

Key words: Vespertilionidae, Molossidae, Nyctalus furvus, Tadarida teniotis, Korea

\section{INTRODUCTION}

Since Corbet (1978) has regarded N. noctula motoyoshi Kuroda 1934, which was reported to occur in Korea with no confidence by Kuroda $(1934,1938)$, as a synonym of Vespertilio superans Thomas 1898, N. aviator Thomas 1911 has been known as the only species of Nyctalus Bowdich 1825 in Korea. On the other hand, a small-sized specimen of Nyctalus which is much smaller than N. aviator but is similar with N. furvus Imaizumi and Yoshiyuki 1968, which has been known as an endemic species in Japan, in size and external and internal (skull, teeth and baculum) morphologies was collected at Busan. It is new to the Korean fauna. In addition, the free tailed bat, Tadarida teniotis (Rafinesque) 1814, has not been recorded in Korea since 1928 (Ognev, 1928) until two females were collected at Busan in this study, although Kishida and Mori (1931) also reported the occurrence of the species with no collecting record. Descriptions of external and internal (skull, teeth and humerus) characteristics with illustrations in both species are provided in the present study.

The measurements unit is in millimeter.

*To whom correspondence should be addressed

Tel: 82-51-620-4642, Fax: 82-51-620-4645

E-mail: yhyun@ks.ac.kr

\section{SYSTEMATIC ACCOUNTS}

Phylum Chordata

Class Mammalia

Order Chiroptera

Family Vespertilionidae

$1 *$ Nyctalus furvus Imaizumi and Yoshiyuki, 1968

(Figs. 1-3)

Nyctalus furvus: Imaizumi and Yoshiyuki, 1968, p. 127, figs. 1,2 .

Material examined. One adult male (No. Nf 1) collected at Daeyeon-dong Kyungsung University Busan Korea, 16 November 1995.

Measurements. Forearm 48.50, head and body 69.95, tail 42.20, hind foot (cum unguis) 12.25, tibia 20.50, ear 15.70, tragus 5.70, third digit 89.95 , fifth digit 52.45 , second metacarpal 49.40, third metacarpal 50.45, fourth metacarpal 49.00, fifth metacarpal 39.60, greatest length of skull 17.90, condylobasal length 17.90 , zygomatic width 12.35 , mastoid width 8.55 , interorbital constriction width 5.20 , breath of braincase 9.40 , depth of braincase 6.65 , mandible length 12.82, maxillary tooth-row length 7.00 , humeral length 30.30 , proximal epiphysis width of humerus 4.55 , distal epiphysis width of humerus 3.05 .

Descriptions. External characters. Muzzle broad, nostrils large and protrudes slightly outward (Fig. 1). The region

1*작은멧박쥐 (신칭) 


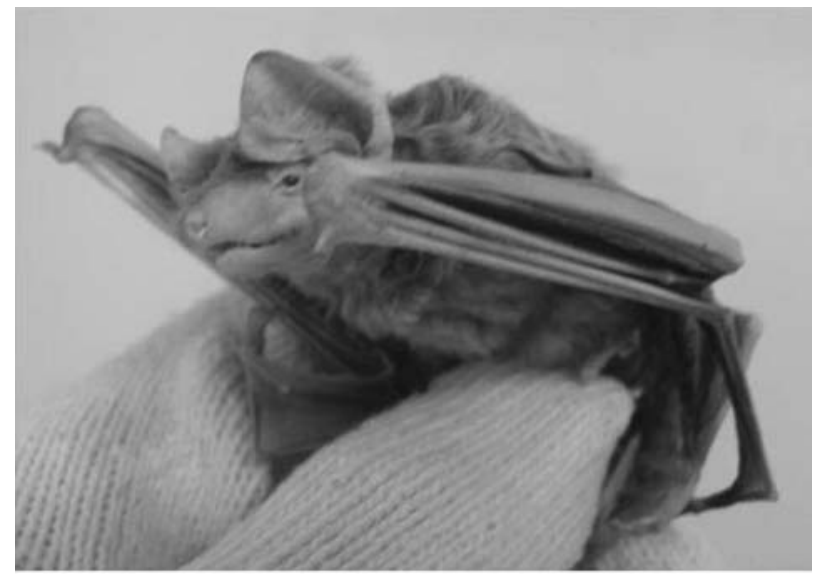

Fig. 1. Nyctalus furvus collected at Busan, 16 November 1995 (Nf1), decolorized due to long-termed preservation in alcohol.

between nostrils wide and evidently concaved in the center. Ears as wide as the length. Internal border of conch abruptly convex forming a right angle below the center, and nearly straight above to the broadly rounded tip. External border of conch shows a convexity with a very slight concavity at the center. Tragus short, whose internal border concave, the external border convex, and the apical portion greatly expanded. Basal one third of posterior surface of the conch and the base of tragus covered with hairs. Antitragus low and wide. Wing long and narrow (III/V, the ratio of third digit length to the fifth digit length, 1.71). Plagiopatagium inserts at the base of metatarsus of the first toe. Hind foot with claw about $60 \%$ of tibia in length. Calcaneum occupies about half the length of lateral border of uropatagium. Keel distinct, about $2 \mathrm{~mm}$ in width. Tail about $42 \mathrm{~mm}$ in length, occupies about $60 \%$ of the length of head and body. Terminal tail vertebra scarcely free beyond the posterior edge of uropatagium. Wing membranes furred on the dorsal and ventral surfaces from the middle of upper arm to the knee, and also loosely furred with short hairs on the under surface of antebrachial membrane and behind the forearm as well as on the basal one third of uropatagium. Due to the decolorization of the specimen owing to the long-termed preservation in alcohol, the color of fur and wing membrane is not described. According to Yoshiyiki (1989), however, general color is dark yellowish brown and the hairs are darker at base than tip.

Skull. Rostrum and braincase broad (Fig. 2). Rostrum much shorter than braincase. Braincase rectangular in figure; the wide mastoid width almost equal to the length from the interorbital region to the occipital region. Depth of braincase $71 \%$ of its breadth. Zygomatic width $12.4 \mathrm{~mm}$, and $69 \%$ of the condylobasal length. Anterior naris large, its greatest width $(3.2 \mathrm{~mm})$ shorter than the greatest length $(4.5$ $\mathrm{mm}$ ), its posterior border extending to the level of middle of upper anterior molar (M1). Temporal crest and sagittal crest low but obvious. Lambdoidal crest distinct and curves slightly forward at the point of junction with sagittal crest. Postorbital ridge evident but low. Lateral profile of skull almost straight from incisor to lambdoidal crest, although somewhat convex in front of the lambdoidal crest. Ante-orbital foramen small and the posterior margin of the foramen extending to the level of anterior border of anterior upper molar (M1). Lacrimal foramen locates slightly behind the ante-orbital ridge. Palatal emargination large, its posterior margin extending to the level of posterior margin of upper posterior premolar ( $\mathrm{P} 4)$. Auditory bullae relatively large, the transverse diameter slightly narrower than the distance between the bullae.

Dental formula. I 0.2.3. C 1. P 0.2.0.4. M 1.2.3.

$$
\text { i 1.2.3. c 1. p 0.2.0.4. } \mathrm{m} \mathrm{1.2.3.=34}
$$

Teeth. In maxilla, inner incisor (I2) slender, with small secondary cusp or not, as wide as outer incisor (I3) and nearly one quarter of canine $(\mathrm{C} 1)$ in crown area. The shaft of I 2 directed slightly inward, and the tip slightly higher than the upper border of cingulum of C1. Outer incisor (I3), whose cingulum is well-developed, as high as the upper border of well-developed cingulum of I2. The secondary cusp of I3 small but distinct and locates postero-outwardly to the main cusp. Canine $(\mathrm{C} 1)$ stout, triangular in transverse section. Anterior premolar (P2) minute, about $1 \mathrm{~mm}$ in diameter. Posterior premolar (P4) wider than half of first molar (M1) in crown area. Both protocone and hypocone of upper molars distinct but low. Posterior upper molar (M3) about half as wide as M1 in crown area. In mandible, three incisors scarcely imbricated and form a wide $\mathrm{V}$-shaped row between canines. Canine (c1) concaved in the posterior cutting edge has the distinct cingulum. Two premolars (p2, p4) contact each other; $\mathrm{p} 4$ very slightly wider than $\mathrm{p} 2$ in crown area; $\mathrm{p} 2$ about half as wide as c1 in crown area; $\mathrm{p} 4$ about half as high as $\mathrm{c} 1$ in height; well-developed cingulum forming small but conspicuous antero-internal and postero-internal cusps. All the lower molars have distinct hypoconid and entoconid, and anterior (m1) and middle (m2) molars almost equal in crown area, and both are slightly wider than the posterior (m3).

Humerus. Humeral shaft nearly cylindrical, head ellipsoidal, sideways long (Fig. 2). Trochiter considerably higher than head. Trochin as high as head. Anterior pit considerably deep. Pectoral ridge more than one sixth of humerus in length, curved at proximal one third. Medial ridge considerably wide proximally. Lateral knob obsolete. Capitulum divided into inner and lateral ridges (in the ratio of two to one in width) by a moderately deep groove oblique slightly to the humeral axis. Wide and flat trochlea much larger than 

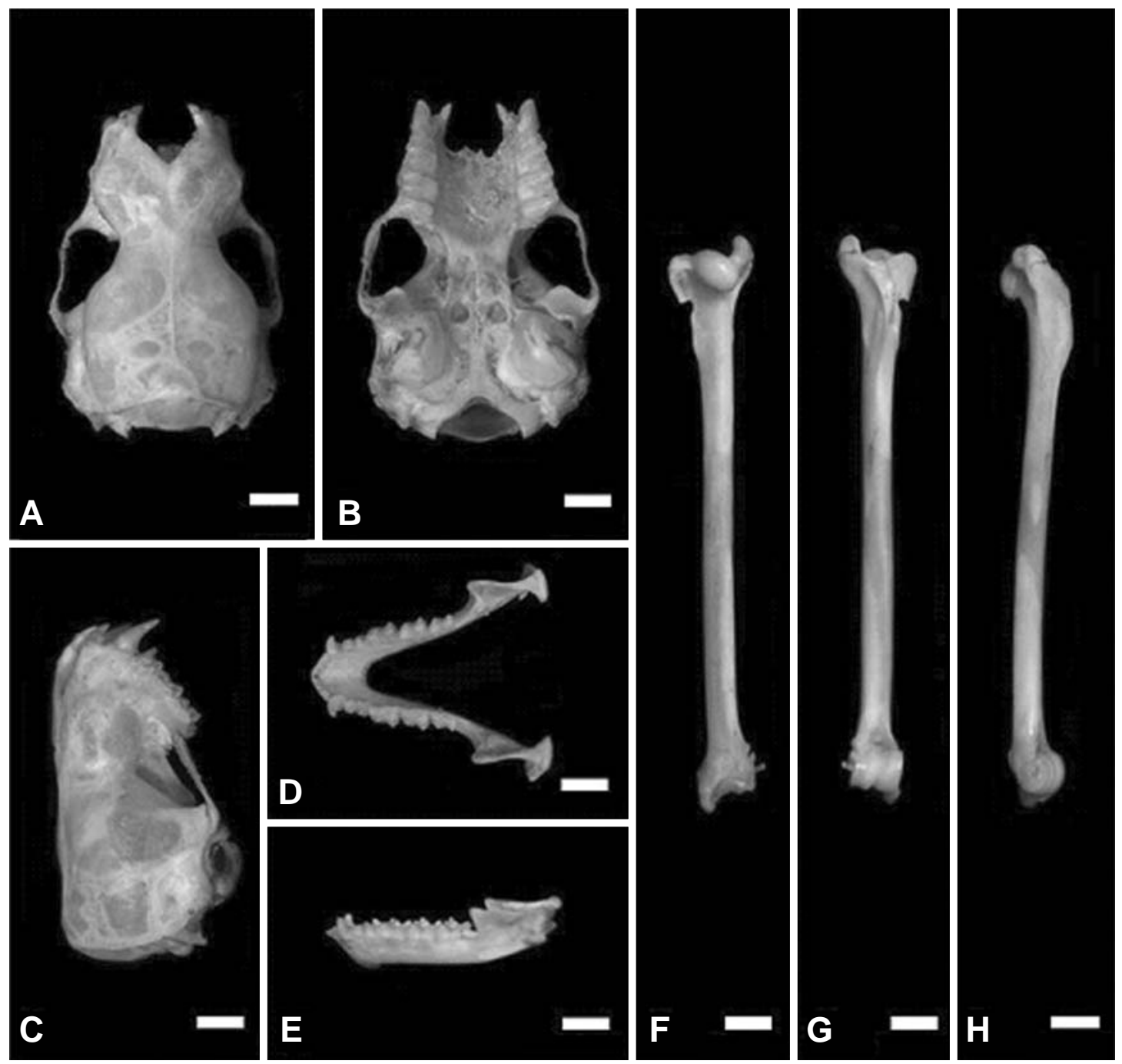

Fig. 2. Skull and right humerus of Nyctalus furvus (Nf1). A, B and $\mathrm{C}$, dorsal, ventral and lateral aspects of cranium, respectively; D and $E$, ventral and lateral aspects of mandible; F, $G$ and $H$, posterior, anterior and lateral aspects of humerus, respectively. Scale bars $=2.5 \mathrm{~mm}(\mathrm{~A}-\mathrm{H})$.

the inner ridge of capitulum. The deep groove between the trochlea and the inner ridge also slightly oblique to the humeral axis. Medial epicondyle small and knob-like. Spinous process terminated at considerably lower level than distal end of trochlea. Distal epiphysis narrow; DW/PW, 0.67. Distal articular surface almost concentric against the humeral axis. Lateral epicondylar crest well developed in general. Olecranon fossa pocket-like and deep. Lateral margin of olecranon fossa reaches behind the capitular lateral ridge. Radial fossa deep.

Baculum. Baculum, consisting of ampulla and body portion, curved near the distal end of the ampulla in lateral view (Fig. 3). The tip of the body is divided into three parts. The greatest length $7.8 \mathrm{~mm}$.
Remarks. The species examined is similar to the Japanese lesser noctule bat in appearance, but is slightly different in the external and internal morphology from the Japanese specimen (Yoshiyuki, 1989). That is, the terminal tail vertebra is scarcely free beyond the posterior edge of uropatagium in the Korean specimen whereas it is $2 \mathrm{~mm}$ free beyond the posterior edge of uropatagium in the Japanese specimen; the posterior border of anterior naris extends to the level of middle of upper anterior molar (M1) in the former whereas it extends to the level of posterior margin of the M1 in the latter; I2 lacks secondary cusp in the former whereas it has small but evident secondary cusp in the latter; and the baculum is longer $(7.8 \mathrm{~mm})$ and lacks longitudinal groove on the ventral surface in the former whereas it is shorter $(6.0 \mathrm{~mm})$ 


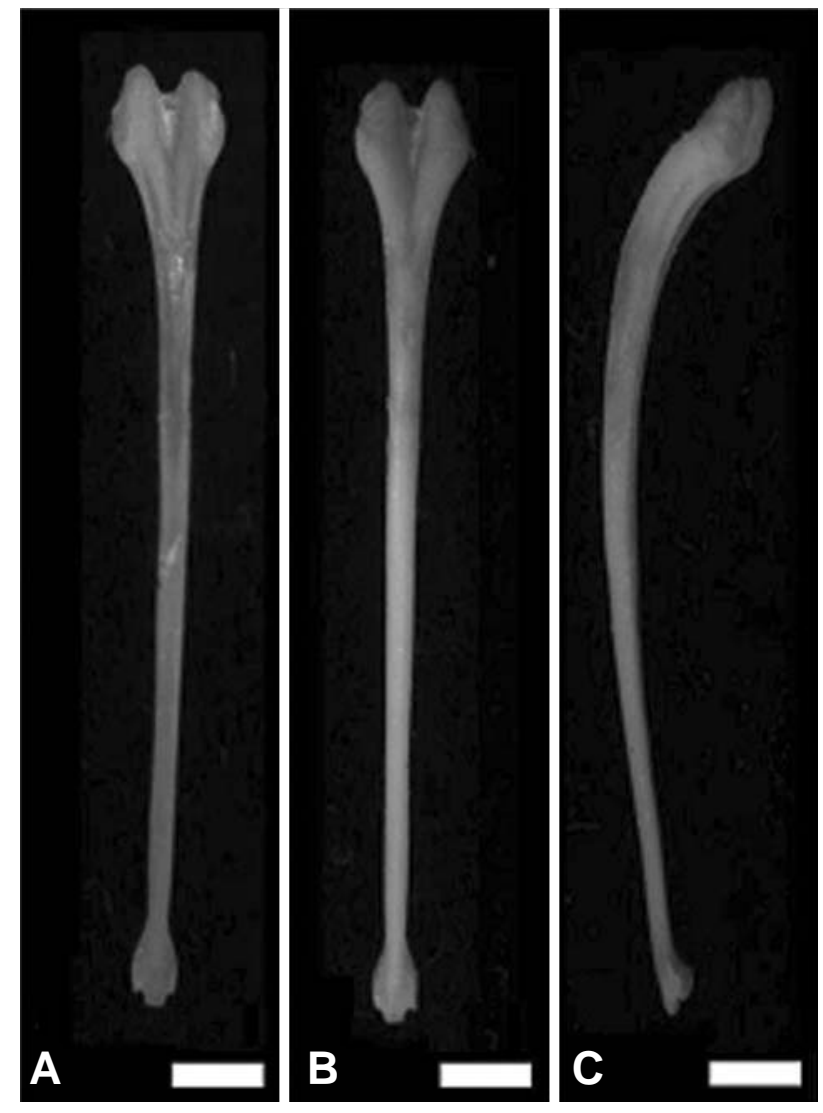

Fig. 3. Baculum of Nyctalus furvus (Nf1). A, B and C, dorsal, ventral and lateral views, respectively. Scale bars $=1 \mathrm{~mm}(A-C)$. and has longitudinal groove in the latter. Due to the addition of this species to the South Korean bat fauna, the South Korean bat fauna is composed of a total of twenty one species and one subspecies belonging to three families.

Distribution. Korea, Japan, China (?).

\section{Family Molossidae}

Tadarida teniotis (Rafinesque) 1814 (Figs. 4, 5)

Cephalotes teniotis Rafinesque, 1814, p. 12.

Nyctinomus teniotis: Thomas, 1891, p. 182.

Nyctinomus insignis: Ognev, 1928 (Ognev 1962), p. 484487.

Tadarida septentrionalis: Kishida (in Kishida and Mori), 1931, p. 379.

Tadarida teniotis: Ellerman and Morrison-Scott, 1951, p. 134; Corbet, 1978, p. 63.

Material examined. Two adult females collected at Haeundae-gu Busan Korea, 7 December 2002 (No. Tt 1) and 24 November 2006 (No. Tt 2), respectively.

Measurements. No. Tt 1: Forearm 58.90, head and body 81.00, tail 47.30, hind foot (cum unguis) 11.30, tibia 19.80, ear 22.80, tragus 5.50, third digit 113.30, fifth digit 59.10, second metacarpal 56.85, third metacarpal 58.40, fourth metacarpal 54.05, fifth metacarpal 33.85, greatest length of skull 24.85, condylobasal length 24.25 , zygomatic width 13.95, mastoid width 13.10 , interorbital constriction width 5.15 , breath of braincase 11.60 , depth of braincase 7.55 , man-

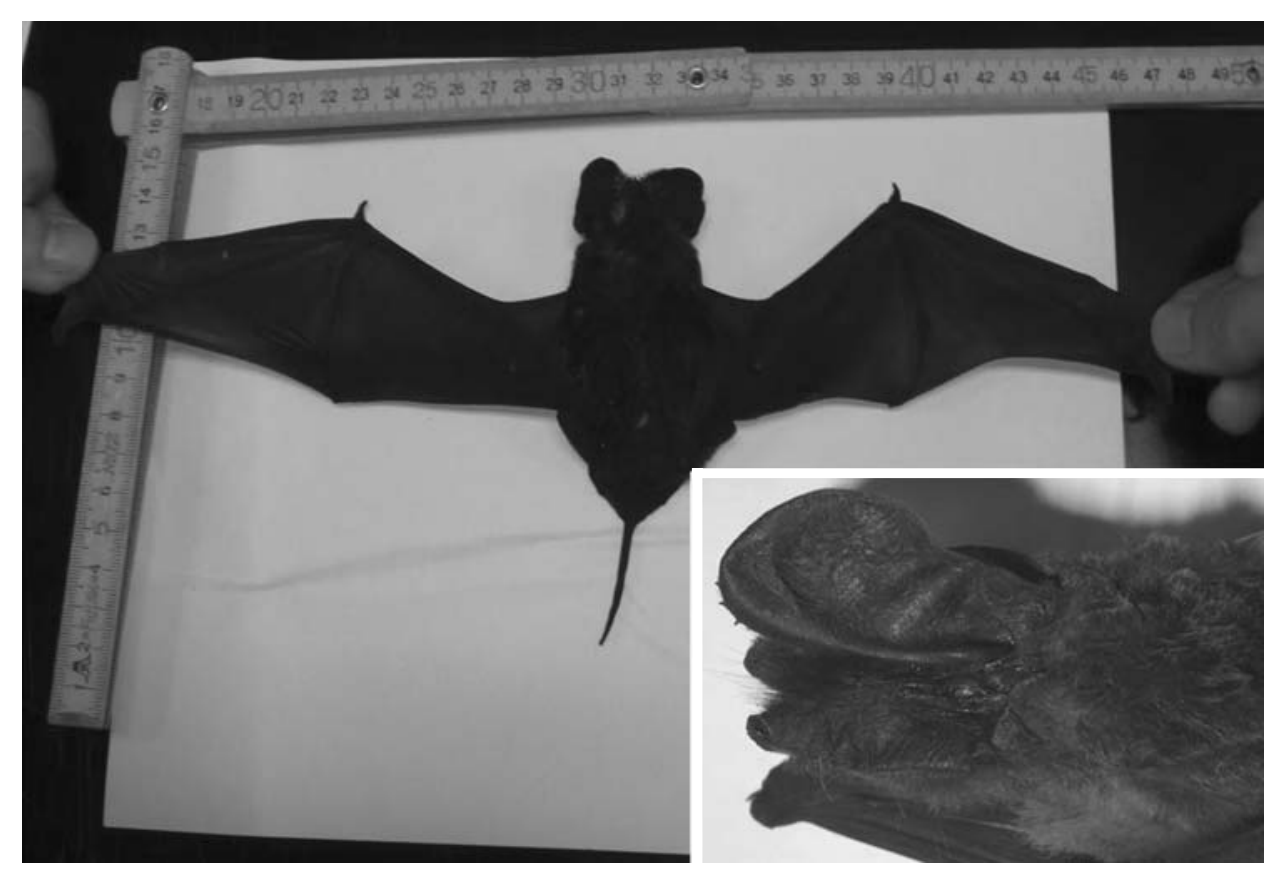

Fig. 4. Tadarida teniotis collected at Busan, 24 November 2006 (Tt2). Inset: the profile of the species. 

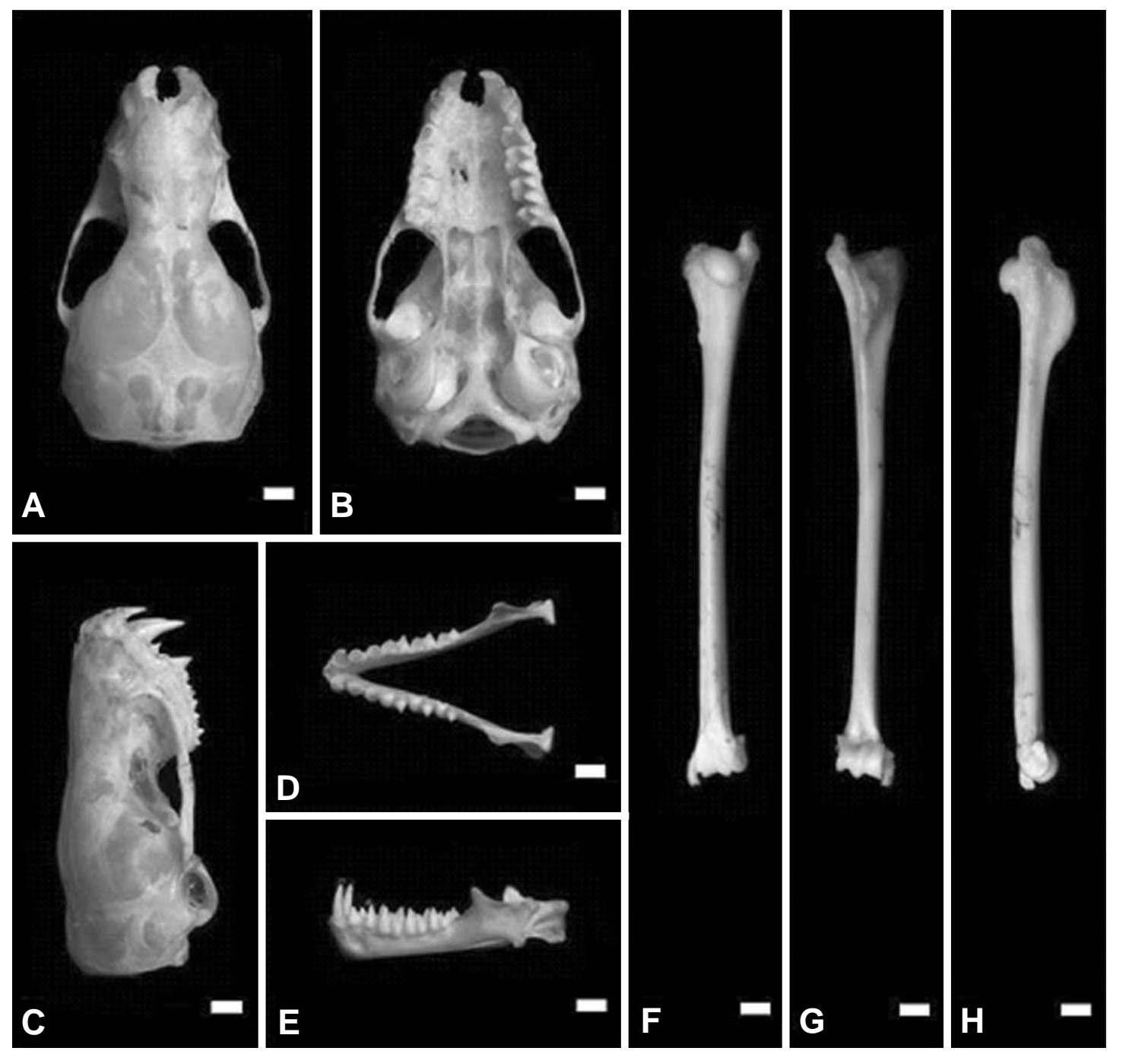

Fig. 5. Skull and right humerus of Tadarida teniotis (Tt2). Alphabetical symbols as in Fig. 1 . Scale bars=2 mm (A-H).

dible length 17.80 , maxillary tooth-row length 9.30 , humeral length 34.70, proximal epiphysis width of humerus 5.25 , distal epiphysis width of humerus 3.70. No. Tt 2: Forearm 61.00, head and body 85.00 , tail 51.70, hind foot (cum unguis) 13.10, tibia 19.70 , ear 27.40 , tragus 6.20 , third digit 114.40 , fifth digit 60.00 , second metacarpal 57.00, third metacarpal 59.40 , fourth metacarpal 56.50, fifth metacarpal 34.05, greatest length of skull 24.65, condylobasal length 23.85, zygomatic width 14.40 , mastoid width 13.00 , interorbital constriction width 5.05, breath of braincase11.90, depth of braincase 7.75 , mandible length 19.10 , maxillary tooth-row length 9.30, humeral length 33.40, proximal epiphysis width of humerus 5.30, distal epiphysis width of humerus 3.80.

Descriptions. External character. The species is easily distinguished from the other species occurring in Korea by the very large and thick ears and the long free tail projecting beyond the posterior edge of uropatagium (Fig. 4 and inset). Body heavy and robust. Muzzle wide, protrudes beyond the upper lip. Nostrils open forward and slightly outward. The upper surface of the nostrils almost naked, and the lower border concaved at middle is lined with a row of small horny excrescences, about 20 in number, and the similar small horny excrescences, about 10 in number, also stand in line at the center between the nostrils. Large and thick ears joined at the internal bases and have a considerably large vertical fold protruding forward at about an internal quarter of the ear and has 9 to10 transverse wrinkles in the internal surface. Upper internal surface and outer border of the vertical fold, and the internal-upper and the external-basal one third surface of the conch are densely furred with hairs, although the front side of the vertical fold almost naked. The round outer margin of the conch, slightly concaved at basal one third and ob- 
liquely wrinkled at base, is furred with fine and short hairs. Tragus small and squarish, $6 \mathrm{~mm}$ in length, a quarter to a fifth of the ear in length, and furred with relatively long hairs on the blunt apical portion. The internal border of tragus shorter than the external border. Antitragus $7.5 \mathrm{~mm}$ in width. Upper lip has 8 to 10 wrinkles at both sides somewhat external to the nostrils, and both outermost ends of the lip droop downward. Wing very long and narrow (III/V, 1.90, 1.91). Plagiopatagium inserts at slightly upper portion of the ankle. The furred area of body extends to the line joining the middle of humerus with knee on both dorsal and ventral surfaces of the wing at which no membrane is present. Hind foot with claw, $57-67 \%$ of tibia in length, has an evident and round pad $2 \mathrm{~mm}$ in diameter in the middle of sole. Tail vertebrae about $29 \mathrm{~mm}$ free beyond the posterior edge of uropatagium. Calcaneum thick and as long as the tibia. Keel absent. Fur very dense and uni-colored, although the lower part slightly paler than the upper part in color. Dorsal fur, velvet-like, grayish white at base but blackish gray-brown at tip, while ventral fur light gray at base and gray-brown at tip. Uropatagium sparsely furred with short hairs on the ventral side. Ear and wing membranes opaque, black brown in color.

Skull. Skull relatively long and narrow (Fig. 5). Rostrum relatively short in length. Braincase relatively low; depth of braincase approximately $65 \%$ of its breadth, and $58-60 \%$ of the mastoid width. Zygomatic width approximately 14.0$14.5 \mathrm{~mm}$ and $57.5-60 \%$ of the condylobasal length. The posterior border of anterior naris extending to the anterior level of anterior upper premolar (P2). Temporal crest and sagittal crest undeveloped. Lambdoidal crest obvious laterally but indistinct in the center. Lateral profile of skull almost straight from the posterior border of anterior naris to the lambdoidal crest, although somewhat concaved at about the posterior third of braincase. Posterior margin of ante-orbital foramen extending to the central level of posterior upper premolar (P4). Ante-orbital ridge evident and lacrimal foramen locates behind the ridge and not exposed. Palatal emargination small; its posterior margin extending to the level of anterior margin of upper canine (C1). Auditory bullae large, cochlea conspicuously exposed.

Dental formula.I 0.2.0. C 1. P 0.2.0.4. M 1.2.3.

$$
\text { i 1.2.3. c 1. p 0.2.0.4. } \mathrm{m} \mathrm{1.2.3.=32}
$$

Teeth. In maxilla, the cone-shaped single incisor (I2) is one of the important characteristics that distinguishes this species from the other species inhabiting Korea. The incisor half as high as canine (C1). The space between $\mathrm{I} 2$ and $\mathrm{C} 1$ subequal to the diameter of I2. The tip of I 2 directed slightly inward. Canine $(\mathrm{C} 1)$ twice as high as the upper posterior premolar (P4). Anterior premolar (P2) minute, lower than half of the $\mathrm{I} 2$ in height. Posterior premolar $(\mathrm{P} 4)$ half as wide as the first molar (M1) in crown area. Anterior molar (M1) slightly wider than M2 in crown area and similar to M2 in shape. Protocone, metapocone, paracone and hypocone of both M1 and M2 very large, another important characteristics distinguishing itself from the other species inhabiting Korea. Posterior upper molar (M3) smaller than M1 or M2, and similar to P4 in size. In M3, the metacone smaller than the paracone, and the hypocone is lacking. In mandible, all the teeth stand close to each other. Three incisors each bifid. Anterior incisor (i1) as large as middle incisor (i2), and posterior incisor (i3) slightly smaller than i2. Canine (c1) wider than anterior (p2) and posterior (p4) premolars in crown area, and higher than twice the height of $\mathrm{p} 2$ or $\mathrm{p} 4$. Anterior premolar (p2) slightly lower but slightly wider than $\mathrm{p} 4$ in height and crown area, respectively. Anterior molar (m1) slightly larger than middle molar (m2) in height and crown area, and posterior molar (m3) slightly narrower than $\mathrm{m} 2$ in crown area. All the cusps of molars distinct.

Humerus. Humeral length about 34 mm (Fig. 5). Head elongated oval in shape. Trochiter considerably higher than head. Anterior pit very deep. Medial ridge wide proximally, and as long as pectoral ridge. Lateral knob absent. Pectoral ridge wide and short, about one fifth of humerus in length; and highest at the middle in lateral view. Trochlea which is as wide as the capitular inner ridge separated with the capitulum by a relatively shallow groove, oblique to the humeral axis. Lateral ridge of capitulum, slightly smaller than the inner ridge, is separated with the inner ridge by another groove which is relatively deep and oblique to the humeral axis. Medial epicondyle narrow. Spinous process terminated at slightly lower level than distal end of trochlea. Distal epiphysis width considerably narrow (DW/PW, 0.71). Lateral epicondylar crest distinct. Olecranon fossa obsolete. Radial fossa pocket-like, very deep and wide.

Remarks. The free tailed bat has not been recorded in Korea since 1928 (Ognev, 1928) until two females were collected at Busan in this study, although Kishida and Mori (1931) reported the occurrence of the species with no collecting record as mentioned above. The free tailed bat occurring Far Eastern Asia has been regarded as a subspecies of $T$. teniotis insignis, by Ellerman and MorrisonScott (1951, 1966), Corbet (1978) and Corbet and Hill (1980). Yoshiyuki (1989), however, regarded the free tailed bat collected from Japan as a full species, T. insignis, judging from the fact that Japanese form is different from T. teniotis in the height of braincase and muzzle, the dorsal coloration, the morphology of anterior palatal emargination of the skull, the lateral view of mandible and the insertion site of the plagiopatagium. She also thought that the free-tailed bat in Far Eastern Asia, such as China and Korea is the same species as the Japanese form. However, the bat examined in this study is rather similar to those of $T$. teniotis and different from the 
Japanese form in some characters mentioned above, such as the dorsal fur coloration (unicolored in the former versus bicolored in the latter), the shape of keel (absent in the former versus present in the latter) and anterior palatal emargination (short in the former versus long in the latter), and the insertion site of the plagiopatagium (upper part of ankle in the former versus basal one third of tibia in the latter). Accordingly, the free tailed bat occurring in Korea is identified as T. teniotis in the present study. As I have not observed many specimens of various subspecies yet, however, the identification of this free tailed bat at the subspecies level is deferred for the present.

Distribution. Korea, China, Taiwan, Japan.

\section{ACKNOWLEDGEMENTS}

I wish to express my profound thanks to the former professor of the Agricultural Univeristy of Tokyo, Dr. Mizuko Yoshiyuki, one of the most noted bat specialists, for the valuable revision of the manuscript. I also wish to thank Dr. JiHye Kim, Ms. Ji-Hyeon Oh and Mr. Jae-Boung Jung, the research members of the Zoological Laboratory of Kyungsung University, for their sincere assistance in preparing manuscript. This research was supported by the Kyungsung University Research Grant in 2009.

\section{REFERENCES}

Corbet, G.B., 1978. The Mammals of the Palaearctic Region: a Taxonomic Review. Br. Mus. Nat. Hist., pp. 37-62.

Corbet, G.B. and J.E. Hill, 1980. A World List of Mammalian Species. Br. Mus. Nat. Hist., pp. 1-226.

Ellerman, J.R. and T.C.S. Morrison-Scott, 1951, 1966. Checklist of Palaearctic and Indian Mammals 1758 to 1946 . Br Mus. Nat. Hist., Lond., pp. 90-189.

Imaizumi, Y. and M. Yoshiyuki, 1968. A new species of insectivorous bat of the genus Nyctalus from Japan. Bull. Nat. Sci. Mus. Tokyo, 11: 127-134.

Kishida, K. and T. Mori, 1931. On distribution of the Korean land mammals. Zool. Mag., Tokyo, 43: 372-391.

Kuroda, N., 1934. Mammals. In Siebold's Fauna Japon, Tokyo, Vol. 3, Japanese ed., p. 3.

Kuroda, N., 1938. A List of the Japanese Mammals. Privately published, Tokyo, pp. 1-100.

Ognev, S.I., 1928. The Mammals of Eastern Europe and Northern Asia. Vol. 1, Insectivora and Chiroptera. Moscow. English translation: Jerusalem, 1962. pp. 1-484.

Rafinesque, 1814. Precis des decouverts somiologiques, p. 12.

Thomas, O., 1891. The duke of Bedford's zoological exploration in eastern Asia. Proc. Zool. Soc. Lond., 1891: 182.

Yoshiyuki, M., 1989. A Systematic Study of the Japanese Chiroptera. Nat. Sci. Mus., Tokyo, pp. 1-242. 